\title{
Physician-Friendly States for Mental Health: A Comparison of Medical Licensing Board Applications
}

\author{
Pamela Wible, ${ }^{1}$ Arianna Palermini ${ }^{2}$ \\ ${ }^{1}$ Family Physician, Founder Ideal Medical Care, Eugene, OR, USA; ${ }^{2}$ Medical student
}

\begin{abstract}
Do medical boards undermine physician mental health by breaching physician confidentiality and privacy? We analyze the initial medical licensing process in each state to determine if qualified applicants who report mental illness experience discrimination. We then identify the most favorable states for physician mental health.
\end{abstract}

\section{Introduction}

Could a pediatrician in marriage counseling 10 years ago be mandated to disclose her therapy records to the state board? Yes. Could a dermatologist with postpartum depression 3 years ago be required to defend her compe-

Correspondence: Pamela Wible, P.O. Box 5225, Eugene, OR 97405, USA.

Tel.: +1.541.345.2437.

E-mail: roxywible@comcast.net

Acknowledgments: the authors thank all physicians who submitted their lived experiences with medical boards and physician health programs.

Dedication: The article is dedicated to our brothers and sisters in medicine who lost their lives to suicide in pursuit of healing others.

Contributions: AP performed the majority of research to acquire initial licensing applications from all state medical boards. PW drafted manuscript that was edited by both authors.

Conference presentation: portions of prior draft manuscript were presented at Psych Congress in San Diego, California, on October 6, 2019.

Key words: Physician mental health; physician suicide; physician depression; medical boards; physician health programs.

Disclosures: authors report no financial disclosures or conflict of interest.

Funding: research project was unfunded. Authors were unpaid volunteers.

Received for publication: 31 October 2019.

Accepted for publication: 14 November 2019.

This work is licensed under a Creative Commons Attribution NonCommercial 4.0 License (CC BY-NC 4.0).

${ }^{\circ}$ Copyright: the Author(s), 2019

Licensee PAGEPress, Italy

Qualitative Research in Medicine \& Healthcare 2019; 3:107-119 doi:10.4081/qrmh.2019.8649 tence before the board? Yes. Should a medical student worry that a licensing board might read his psychological evaluation for test anxiety? Yes.

State medical boards may access applicants' confidential health records and require that all 3 individuals defend their competence to practice medicine. Are medical boards injuring physicians by violating their rights? Many, like this physician, say yes.

Why are mental health questions still allowed to be on there? I have had postpartum anxiety/depression three times now and I feel like it is none of their damn business. So, I have lied about it on my applications. Also, I feel these questions could contribute to doctors not seeking help, especially for serious problems that could require a mental health hospitalization. Do these questions have an adverse effect on doctors and medical students presenting (or not) for care they may desperately need?

We all desire competent, healthy doctors who deliver excellent patient care. State medical boards exist to protect the health, safety, and welfare of patients through licensing, investigating, and disciplining physicians. Their mission is to protect the public from impaired physicians, yet medical boards may be impairing physicians' access to confidential compassionate health care by subjecting doctors to mental health questions that violate United States law. One doctor reports:

After reading an article about one woman's journey through hell after being honest on those application questions, I sought care an hour away. I drove an hour in another direction to nervously fill prescriptions for antidepressants. I required several meds to stop thinking of suicide all day every day. My suicidal thoughts were 100\% workrelated.

Suicide is an occupational hazard of the medical profession. ${ }^{1}$ Though students enter medicine with their mental health on par with or better than their peers, they are 3 times more likely to kill themselves, according to the 
American Medical Student Association. In some residency programs $75 \%$ of interns meet criteria for major depression. ${ }^{2}$ Suicide risk increases with untreated mental illness. Physicians who die by suicide are less likely to be receiving mental health care compared with non-physician suicides. Physicians are more likely to self-medicate for anxiety, depression, and suicidality - with tragic outcomes.

Doctors are reported to have the highest suicide rate of any profession - even higher than the military-according to findings presented at the 2018 American Psychiatric Association annual meeting. ${ }^{3}$

What is causing our physician mental health crisis?

Physicians are routinely exposed to tragedy and death resulting in occupationally induced anxiety, depression, and Post-Traumatic Stress Disorder (PTSD). Yet doctors receive no routine on-the-job support. Instead, they risk punishment when asking for help. State boards, hospitals, even health plan and malpractice insurance companies interrogate doctors about their mental health, read their confidential medical records, and then deny health plan participation, medical liability coverage, hospital privileges, and state licensure. Doctors with occupational distress may be referred to Physician Health Programs (PHPs) where they are required to participate in 12-step addiction recovery with witnessed random urine drug screens - even when they have never used drugs as this psychiatrist reports:

I'm amazed at the punitive terms I've had to face in recovering professionally from a depressive episode for which I was hospitalized last year. One of my requirements is to be urine tested for substance abuse, despite multiple demeaning assessments that have rendered the clear verdict that I don't have a substance use problem. I've had to attend costly treatments for 'professionals' in which I am the only female in a group of male physicians who have had sex with their patients or have become assaultive with staff. Any efforts on my part to point out that I don't quite 'fit' are taken as further evidence of my pathology. I'm a single parent as well, so that each of these 'treatments' I'm required to attend takes me away from my two children for extended periods of time. Throughout all of this, nobody has told me how common my feelings are - that a large number of doctors feel depressed and suicidal at times. Rather, I've been told that my actions are unheard of for someone in mental health and may preclude me from ever providing therapy again since 'we tell patients to never give up hope, but you did'. Hopefully, in the near future this won't be a taboo subject, and there will be places for those like me to seek responsible and confidential care.

While PHPs have been effective for some physicians with substance abuse, physicians have also died by suicide under the care of these programs. ${ }^{4}$ PHPs hold a monopoly in the provision of state-board-sanctioned physician assistance services in most states. To avoid punishment by PHPs and boards (that may restrict licensure and publish doctors' mental health diagnoses online) physicians drive hundreds of miles out of town, use fake names, and pay cash for off-the-grid care. One doctor reports:

I've been in practice 20 years and have been on antidepressants and anxiolytics for all of that time.

I drive 300 miles to seek care and always pay cash.

I am forced to lie on my state relicensing every

year. There is no way in hell I would ever disclose this to the medical board - they are not our friends.

Results from a 7-year investigation of 1300 physician suicides reveal that doctors (and medical students) die by suicide due to fear of seeking care that would be disclosed on their applications for residency, hospital privileges, and state licensure. Fear of seeking treatment leads to delayed diagnoses thereby increasing anxiety, depression, substance abuse, and suicide. ${ }^{5}$ One doctor shares:

Do you know what really hurts? The fact that anyone can look me up on the Internet and read my dirty laundry. I'm publicly shamed (by my medical board), punished for being ill. I will only know peace when I am gone.

The American Medical Association (AMA) Code of Medical Ethics upholds the right of confidentiality for all seeking health care. A therapeutic alliance requires trust to allow full disclosure of sensitive and personal information. Individuals receiving care believe their medical records will be safeguarded and only released with their consent. Physicians hold confidentiality sacred and take an oath to preserve it at all costs. Physicians are understandably shocked when their own personal health information is accessed by employers, hospitals, and medical boards under the pretense of public safety.

Health Insurance Portability and Accountability Act (HIPAA) provides data privacy and security provisions to safeguard medical information for all US citizens. Information about health status, provision of health care, or payment for health care that is collected by a covered entity (such as a doctor or health center) and can be linked to an individual is Protected Health Information (PHI) under federal law. Though physicians must uphold patient HIPAA rights or face harsh penalties, physicians are expected to waive their own HIPAA rights to medical institutions such as state boards.

The Americans with Disabilities Act (ADA) of 1990 states: No covered entity shall discriminate against a qualified individual on the basis of disability in regard to job application procedures, the hiring, advancement, or discharge of employees, employee compensation, job training, and other terms, conditions, and privileges of employment. Yet competent physicians suffer repeated invasion of privacy and discrimination by medical institutions in violation of the ADA. 


\section{Materials and Methods}

We queried via social media and emailed 6000 US physicians: Have you ever faced discrimination, limitation of license, or delay/denial of your medical license due to mental health issues? A selection of de-identified submissions is published with permission. We analyzed mental health questions on medical board initial licensing applications from all 50 states and the District of Columbia. Most applications were accessed online or by portable document format. When only available through a portal, a login was created. When an application was unavailable or no mental health question was identified, the board was contacted by email and/or phone to confirm the absence or presence of mental health questions and verify wording when present. All mental health and impairment questions were organized on a spreadsheet to compare quantity and quality of questions. Substance use queries were removed. The focus of this research is on non-drug-related endogenous mental health conditions and corresponding questions by medical boards. We italicized key mental health phrases for ease of reading and graded states based on invasiveness of mental health questions into 5 categories $\mathrm{A}$ through $\mathrm{F}$.

Grade A: States with no mental health questions or one or 2 straightforward current impairment question(s) that do not mention mental health.

Grade B: States with progressive mental health question(s) linked to current impairment.

Grade C: States with mental health question(s) spanning the last 5 years.

Grade D: States with have-you-ever questions related to mental health, mental health questions beyond 5 years, or a requirement for peer reference on applicant's mental health.

Grade F: States with highly invasive mental health questions unlinked to current impairment that contain confusing, punitive, or adversarial language.

\section{Results}

Grade A: States with no mental health questions or one or 2 straightforward current impairment question(s) that do not mention mental health.

9 States: Connecticut, Hawaii, Kentucky, Maine, Michigan, Nevada, New York, Pennsylvania, Wyoming.

Connecticut, Hawaii, Michigan, and New York are the most physician-friendly of all states with no mental health or impairment questions.

Kentucky asks: Are you currently suffering from any condition for which you are not being appropriately treated that impairs your judgement or that would otherwise adversely affect your ability to practice medicine in a competent, ethical and professional manner? Maine asks: Are you physically and mentally able to per- form all the essential functions or services necessary to exercise the privileges or services applied for with or without reasonable accommodation? Are you able to perform these functions without significant risk or injury to yourself or others?

Nevada asks: Do you currently have a medical condition which in any way impairs or limits your ability to practice medicine with reasonable safety and skill? If you currently have a medical condition which in any way impairs or limits your ability to practice medicine, is that impairment or limitation reduced or ameliorated because of the field of practice, the setting, the manner in which you have chosen to practice, or by any other reasonable accommodation?

Pennsylvania asks only about drug-related impairment: Do you currently engage in or have you ever engaged in the intemperate or habitual use or abuse of narcotics, hallucinogens, or other drugs or substances that may impair judgement or coordination?

Wyoming has no direct mental health questions, though reference must answer: Does the applicant's health allow for the safe and competent practice of medicine?

Grade B: States with progressive mental health question(s) linked to current impairment.

14 States: California, Illinois, Indiana, Iowa, Maryland, Missouri, New Jersey, New Mexico, North Carolina, South Carolina, Tennessee, Vermont, Virginia, Wisconsin. California asks: Do you currently have any condition (including, but not limited to emotional, mental, neurological or other physical, addictive, or behavioral disorder) that impairs your ability to practice medicine safely?

Illinois asks: Do you now have any disease or condition that presently limits your ability to perform the essential functions of your profession, including any disease or condition generally regarded as chronic by the medical community, i.e., i) mental or emotional disease or condition; ii) alcohol or other substance abuse; iii) physical disease or condition? If yes, attach a detailed statement, including an explanation whether or not you are currently under treatment.

Indiana asks: Do you now have any disease or condition that presently limits your ability to perform the essential functions of your profession, including any disease or condition generally regarded as chronic by the medical community, i.e., i) mental or emotional disease or condition; ii) alcohol or other substance abuse; iii) physical disease or condition?

Iowa asks 5 current impairment questions. The first is: Do you currently have a medical condition which in any way impairs or limits your ability to practice with reasonable skill and safety? Follow-up questions: Are you receiving ongoing treatment or participating in a monitoring program that reduces or eliminates the limitations or impairments caused by either your medical 
condition or use of alcohol, drugs, or other chemical substances? Does your field of practice, or the setting or the manner in which you have chosen to practice, reduce or eliminate the limitations or impairments caused by your medical condition or use of alcohol, drugs, or other chemical substances? The final 2 questions relate to current drug use. Medical condition is defined as any physiologic, mental or psychological condition, impairment or disorder, including drug addiction and alcoholism.

Maryland asks: Do you currently have any condition or impairment (including, but not limited to substance abuse, alcohol abuse, or a physical, mental, emotional, or nervous disorder or condition) that in any way affects your ability to practice your profession in a safe, competent, ethical, and professional manner?

Missouri asks the same questions as Illinois though adds sexual disorder: Do you currently have any condition or impairment which in any way affects your ability to practice in a professional, competent and safe manner, including but not limited to: i) a mental, emotional, nervous or sexual disorder, ii) an alcohol or substance abuse disorder or iii) a physical disease or condition?

States such as Missouri have updated their questions to avoid discrimination against physicians with mental illness reports one psychiatrist:

I have experienced discrimination and delay in getting my Missouri medical license due to my mental illness. I have bipolar disorder in remission for years. Never affected my ability to practice (my only mental illness which has affected my ability to practice has been my PTSD secondary to being a physician). Years ago, the Missouri application asked whether you were diagnosed with a psychotic disorder, and it had schizophrenia and bipolar disorder in parenthesis. So, of course, I had to answer yes. As a result, I had to undergo an additional yearly evaluation by my psychiatrist and he had to write a letter to the board saying that I was safe to practice medicine even though I have a psychotic disorder. My license was always delayed and it was a nightmare renewing every year. Now the Missouri board has removed that question so they must have caught some heat. But I felt very violated and targeted with that question.

New Jersey asks 4 impairment questions. The first is: Do you have a medical condition which is any way impairs or limits your ability to practice medicine with reasonable skill and safety? The next 2 are related to current use of chemical substances and the final question asks about any diagnosis of pedophilia, exhibitionism, and voyeurism. The entire section on Medical Conditions is preceded with a statement about an applicant's Fifth Amendment right against self-incrimination.
New Mexico asks: Do you have a physical or mental condition that would affect your ability, with or without reasonable accommodation, to provide appropriate care to patients and otherwise perform the essential functions of a practitioner in your area of practice without posing a health or safety risk to your patients? If yes, what accommodations would help you provide appropriate care to patients and perform other essential functions?

North Carolina asks: Do you currently have any medical, chemical dependency or psychiatric condition that might adversely affect your ability to practice medicine or surgery or to perform the essential functions of your position? An emergency physician reports:

I was sued. Overwhelmed with grief and fear, I took antidepressants and saw a psychiatrist. I paid cash and considered using a false name. I had already seen the North Carolina Medical Board send a physician to 6 weeks of inpatient alcohol treatment due to a complaint without any proof he was drinking. That saved his license but he owed an astronomical bill.

South Carolina asks: Are you currently being treated for any physical, mental or emotional condition that might interfere with your ability to competently and safely perform the essential functions of practice as a physician?

Tennessee asks: Do you currently have any physical or psychological limitations or impairments caused by an existing medical condition which are reduced or ameliorated by ongoing treatment or monitoring, or the field of practice, the setting or the manner in which you have chosen to practice? Tennessee also asks: Have you ever been diagnosed as having or have you ever been treated for pedophilia, exhibitionism, voyeurism or other diagnosis of a predatory nature? (Reference Grade B Section end note on predatory/criminal behaviors).

Vermont has a section entitled: Medical condition, treatment, use of chemicals or illegal substances. It begins with definitions: The ability to practice medicine is a term that includes: i) The cognitive capacity to make and exercise reasoned medical judgments, and to learn and keep abreast of medical developments; ii) The ability to communicate those judgments and medical information to patients and other health care providers, with or without the use of aids or devices, such as voice amplifiers; and iii) The physical capacity to perform medical tasks and procedures, with or without the use of devices, such as corrective lenses or hearing aids. Medical conditions include physiological, mental or psychological conditions with a non-comprehensive list that includes emotional and mental illnesses, learning disabilities, drug addiction, and alcoholism. Currently means recently enough to have a real or perceived impact on one's functioning as a medical pro- 
fessional. 'Chemical substances' means alcohol, drugs (legal and illegal), and prescribed medications. This section has 3 main questions, each with a follow-up question and place to upload relevant documents. All focus on current impairment. Two relate to substance use and the other reads: do you have a medical condition that in any way impairs your ability to practice medicine in your field of practice with reasonable skill and safety?

Virginia asks: Do you currently have any mental health condition or impairment that affects or limits your ability to perform any of the obligations and responsibilities of professional practice in a safe and competent manner? Currently means recently enough so that the condition could reasonably have an impact on your ability to function as a practicing physician.

Wisconsin has 5 impairment questions: do you have a medical condition, which in any way impairs or limits your ability to practice medicine with reasonable skill and safety? Follow-up questions are: If yes, are the limitations or impairments caused by your medical condition reduced or ameliorated because you receive ongoing treatment (with or without medications) or participate in a monitoring programs? If yes, are the limitations or impairments caused by your medical condition reduced or ameliorated because of the field of practice, the setting, or the manner in which you have chosen to practice? The fourth question is related chemical substance impairment and final question: Have you ever been diagnosed as having or have you ever been treated for pedophilia, exhibitionism, voyeurism?

Note: New Jersey, Tennessee, and Wisconsin have a similar question on criminal/predatory behavior (pedophilia, exhibitionism, voyeurism) as do Alabama, Ohio, Minnesota, Mississippi, and Washington. Medical boards must protect patients from criminal behavior and we do not penalize states for these questions.

Grade C: States with mental health question(s) spanning the last 5 years.

10 States: Arizona, Colorado, Minnesota, Montana, North Dakota, Ohio, Oklahoma, Oregon, Texas, Utah. Arizona lists mental health questions in Confidential

Questions. The primary question: Have you received treatment within the last 5 years for use of alcohol or a controlled substance, prescription-only drug, or dangerous drug or narcotic or a physical, mental, emotional, or nervous disorder or condition that currently affects your ability to exercise the judgment and skills of a medical professional? If so, provide the following: i) A detailed description of the use, disorder, or condition; and ii) An explanation of whether the use, disorder, or condition is reduced or ameliorated because you receive ongoing treatment and if so, the name and contact information for all current treatment providers and for all monitoring or support programs in which you are currently participating. iii) A copy of any public or confidential agreement or order relating to the use, disorder, or condition, issued by a licensing agency or health care institution within the last 5 years, if applicable.

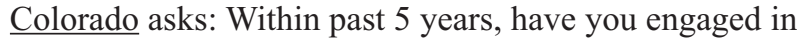
any conduct or exhibited any behaviors that resulted in an impairment in your ability to practice in a safe, competent, ethical and professional manner?

Minnesota asks: Have you within the past 5 years been advised by your treating physician that you have a mental, physical, or emotional condition, which, if left untreated, would be likely to impair your ability to practice medicine with reasonable skill and safety? An affirmative answer requires 5 additional questions regarding current treatment, compliance, and name of treating physician. Minnesota also asks: Have you ever been diagnosed as having or have you ever been treated for pedophilia, voyeurism, or other sexual behavior disorders? We strongly feel that sexual behavior disorders are too broad as focus should be on criminal/predatory conduct only.

Montana asks: Have you been diagnosed within the past 5 years with a physical condition or mental health disorder including potential health risk to the public?

North Dakota asks: Within the last 2 years have you been treated for any physical, mental or emotional condition which impaired or could be said to impair your ability to practice medicine safely and competently?

Ohio asks 4 mental health questions. The first 3 are: In the past 5 years, have you been diagnosed as having, or been hospitalized for a medical condition which in any way impairs or limits your ability to practice medicine with reasonable skill and safety? Are the limitations or impairments caused by your medical condition reduced or ameliorated because you receive ongoing treatment or received treatment in the past (with or without medication) or participate in a monitoring program? Are the limitations or impairments caused by your medical condition reduced or ameliorated because of the field of practice, the setting, or the manner in which you have chosen to practice? If you receive such ongoing treatment or participate in such monitoring program the board will make an individualized assessment of the nature, severity, and duration of the risk associated with an ongoing medical condition. Have each treating physician submit a letter detailing the dates of treatment, diagnosis, and prognosis. A final question is: Have you ever been diagnosed as having, or have been treated for, pedophilia, exhibitionism, or voyeurism? (Reference end note Grade B section on predatory/criminal behaviors).

Oklahoma asks: Do you currently have or have you had within the past 2 years any mental or physical disorder or condition, which, if untreated, could affect your ability to practice competently? 
Oregon has 3 mental health questions. The first: Within the past 2 years, have you participated in a program (other than the Oregon PHP) for evaluation, monitoring, or treatment for any issue in lieu of or as a condition of resolving a matter before a health care program or facility or a regulatory or licensing board or has such action been pending or proposed? Issue includes, but is not limited to, substance use, communication, or boundary issues. (if yes provide full details and dates to include the name and location of the diversion program, regulatory Board, healthcare program or facility, and/or court, and reasons for and results of entering the program). The second: Do you currently have, or have you had within the past 2 years, any physical, mental, or emotional condition which impaired or does impair your ability to practice your health care profession safely and competently? The final question: Within the past 2 years, have you been admitted to any hospital or other treatment facility for any physical, mental or emotional condition or substance use disorder which impaired or does impair your ability to practice your health care profession safely and competently? (If yes to either, provide full details and name of healthcare professional providing treatment. Request the healthcare professional send directly to the Board a statement regarding the ability to safely practice medicine).

Texas has a Mental and Physical Health section with 5 questions with mandatory submission of another form for any affirmative answer. The first 3 relate to selfreferral to the Texas Physicians Health Program, substance use within past 5 years, and physical/neurologic condition impairments within 5 years. The mental health question is: Within the past 5 years, have you been diagnosed with or treated for any: psychotic disorder, delusional disorder, mood disorder, major depression, personality disorder, or any other mental health condition which impaired or does impair your behavior, judgment, or ability to function in school or work? If you answered Yes are the limitations caused by your mental condition or substance abuse/dependency problem reduced or ameliorated because you receive ongoing treatment (with or without medication) or because you participate in a monitoring program? One internist reports:

I am applying for my Texas license and I feel my rights are being violated. I have well-managed depression. I was asked do you have a mental condition - yes, and then I was asked does it affect how you function at work - no. I thought that would be the end of it, but now I need a treating physician statement, a statement from my program director, and I need to justify why I said no to it not affecting how I function at work. I'm required to list all my medications from the past 5 years and all physicians who have treated me.
How is this not a HIPAA violation? Why are they still allowed to do this? My application has been flagged as impaired and needs to go before the board and people who have never met me will decide if I am a danger to my patients. I have no money for a lawyer. If I fight this it can delay my license and my being able to work. My friends with no medical issues were approved months ago and here I am still waiting.

Utah asks: If you are licensed in the occupation/profession for which you are applying, would you pose a direct threat to yourself, to your patients or clients, or to the public health, safety, or welfare because of any circumstance or condition? Have you ever been declared by any court or competent jurisdiction incompetent by reason of mental defect or disease and not restored? Utah's one have-you-ever question is far less invasive than those in Grade D section.

Grade D: States with have-you-ever questions related to mental health, mental health questions beyond 5 years, or a requirement for peer reference on applicant's mental health.

10 States: Arkansas, District of Columbia, Georgia, Idaho, Kansas, Louisiana, Nebraska, New Hampshire, South Dakota, West Virginia.

Arkansas asks: Are you currently suffering from any condition for which you are not being appropriately treated that impairs your ability to practice medicine or to perform professional or medical staff duties in a competent, ethical, and professional manner? If yes, explain. Are you currently, or have you ever been monitored by a Physician Health Committee in any state? If yes, explain, and ask the Physician Health Committee to send documentation of your status.

Non-impaired physicians have been mandated to impaired practitioner programs as retaliation. These programs (PHPs), governed by the Federation of State Physician Health Programs, exist under private contracts in all states except California, Nebraska, and Wisconsin. An occupational medicine physician explains:

PHPs remain largely non-compliant with $A D A$ laws and regulatory guidelines in assessing medical and psychiatric fitness of physicians. They receive revenue from contracts with physician employers and residency programs plus referred medical students/physicians who pay costly out-of-pocket fees or risk career destruction. Physician employers liberally refer to PHPs for virtually any reason. PHPs even encourage third-party referrals. Aggrieved spouses, jilted lovers, market competitors have all successfully required PHP evaluations of physicians.

District of Columbia is a federal district with its own medical licensing board that asks 2 non-drug-related im- 
pairment questions: Do you have a medical condition or have you become aware of any medical condition that impairs or limits your ability to practice your profession? Have you ever engaged in any conduct that either indicated an impairment, or actually impaired, your ability to practice your profession? Two additional questions are: Have you ever entered into a monitoring program for purposes of monitoring your abuse of alcohol, drugs, or other controlled substances? Have you ever entered into a monitoring program for purposes of monitoring your professional behavior including recordkeeping, billing, boundaries, quality of care or any other matter related to the practice of your profession? We find referrals based on any other matter related to the practice of your profession to be broad and subjective given that one anonymous and unsubstantiated complaint can lead to a physician PHP referral and undermine a doctor's career.

Georgia has no impairment or mental health questions though requires 3 peer references to answer: Does this physician have, or has this physician had in the past, any mental or physical illnesses or personal problems that interfere with his/her medical practice? Unlike the single Wyoming (Grade A) peer reference, Georgia requires multiple colleagues to reveal any mental health issue at any time in the life of a physician peer including past personal problems.

Such questions pose barriers to seeking mental health care and create collegial distrust when physicians fear revealing their struggles with peers who may report them to boards. Two physicians explain:

Isn't it more appropriate to ask a reference about a physician's knowledge, reliability, integrityperformance? Mental health questions have a chilling effect that I admit have kept me from seeking mental health support when it would have been wise to do so. Stigma is so severe that I have heard many physicians state that it would be better to die from suicide than be admitted to our hospital's psychiatric unit.

My psychiatrist requested I report to the Georgia Medical Board my inpatient care for a major depressive disorder. They stamped a 5-year private consent order on me whereby I had to submit to random urines (though there was no history of substance abuse). If I knew what I would be subjected to over the next 5 years and the expense of hundreds of urines, I would not have fulfilled his request. The toughest challenge was getting through the red tape with hospital privileges when they found out I had been treated for depression. I know dozens of physicians under psychiatric care for depression. They dare not relay such to the Board secondary to what I endured.

Idaho asks: Have you ever been diagnosed and/or treated for any mental, physical, cognitive condition including substance use disorder that may affect your ability to practice medicine with reasonable skill and safety?

Kansas has 4 impairment questions. The first: Within the last 2 years have you been diagnosed or treated for any physical, emotional or mental illness or disease, including drug addiction or alcohol dependency, which limited your ability to practice the healing arts with reasonable skill and safety? The second on self-medicating: Within the last 2 years have you used controlled substances, which were obtained illegally or which were not obtained pursuant to a valid prescription order or which were not taken following the directions of a licensed health care provider? The third: Have you ever practiced your profession while any physical or mental disability, loss of motor skill or use of drugs or alcohol impaired your ability to practice with reasonable safety? Given widespread sleep-deprivation impairment (and use of stimulants) during residency, nearly all physicians (if responding honestly) would admit yes. The final question: Do you presently have any physical or mental problems or disabilities which could affect your ability to competently practice your profession? One doctor reveals:

I used samples of Paxil and had my spouse write me prescriptions for Lexapro, Buspar, Paxil, and sleeping pills over the years. I did not trust other doctors. I did not want any of this stuff in my records as I did not want to be seen as crazy (this is how many doctors refer to psychiatric patients).

Louisiana asks: In the last 10 years prior to this application have you had any physical injury or disease or mental illness or impairment, which could reasonably be expected to affect your ability to practice medicine or other health profession?

Nebraska asks: Do you currently, or have you had, any physical, mental, or emotional condition which impaired, or does impair your ability to practice your health care profession safely and competently? Within the last 5 years, has any licensing agency or credentialing organization initiated any inquiry into your physical, mental or emotional health? As we noted previously, inquiries can be retaliatory and the question posed by Nebraska would imply physician guilt for having psychological needs.

New Hampshire asks: Have you ever had any physical, emotional, or mental illness which has impaired or would be likely to impair your ability to practice medicine? A physician with postpartum depression decades ago must answer yes leading to invasion of privacy unlinked to current impairment.

South Dakota asks 4 questions. Two are related to drug use and the other 2 are: Do you have a physical, mental or emotional condition which may adversely affect your practice? Have you been treated for or do you have a diagnosis for any Mental Health condition? (If 
yes, please ask your treating provider to send a status letter to the Board office). Phrasing indicates that a physician must reveal any lifetime mental health condition to the board which is invasive and unlinked to current impairment.

West Virginia asks: Have you had any interruption in your practice of medicine which might reasonably be expected by an objective person to currently impair your ability to carry out the duties and responsibilities of the medical profession in a manner consistent with standards of conduct for the medical profession? Have you ever had anything occur which might reasonably be expected by an objective person to currently impair your ability to carry out the duties and responsibilities of the medical profession in a manner consistent with standards of conduct for the medical profession? Though West Virginia mental health questions focus on current impairment and are preferable to the wording of all other states graded D, we have placed West Virginia in this category due to have-you-ever questions.

Grade F: States with highly invasive mental health questions unlinked to current impairment that contain confusing, punitive, or adversarial language.

8 States: Alabama, Alaska, Delaware, Florida, Massachusetts, Mississippi, Rhode Island, Washington.

Alabama asks 3 mental health questions. The first: Within the past 5 years, have you ever raised the issue of consumption of drugs or alcohol or the issue of a mental, emotional, nervous, or behavioral disorder or condition as a defense, mitigation, or explanation for your actions in the course of any administrative or judicial proceedings or investigation; any inquiry or other proceeding; or any proposed termination by an educational institution; employer; government agency; professional organization; or licensing authority? The second: Have you ever been diagnosed as having or have you ever been treated for pedophilia, exhibitionism, or voyeurism? Final question: Are you currently engaged in the excessive use of alcohol, controlled substances, or the illegal use of drugs, or received any therapy or treatment for alcohol or drug use, sexual boundary issues or mental health issues?

The application explains: The term currently does not mean on the day of, or even in the weeks or months preceding the completion of this application. Rather it means recently enough so that the condition referred to may have an ongoing impact on one's functioning as a physician within the past 2 years. We wonder why the application did not instead read within the last 2 years. The final question suggests that applicants must reveal if they have ever received any therapy for mental health issues in their lifetime regardless of current impairment. For this reason, Alabama is graded F.

Alaska ranks worst of all states with 25 yes-or-no questions related to mental health, many invasive have-you-ever- had questions unlinked to current impairment. The first: Has your ability to practice medicine in a competent and safe manner ever been impaired or limited by any condition, behavior, impairment, or limitation of a physical, mental, or emotional nature? Alaska also asks: Since completing your postgraduate training, have you ever been physically or mentally unable to practice medicine for a period of 60 days or longer? The most invasive mental health question we found on any application is: Have you ever been diagnosed with, treated for, or do you currently have: followed by a list of 14 mental health conditions including depression, seasonal affective disorder, and any condition requiring chronic medical or behavioral treatment (Figure 1).

One hospitalist reports:

In residency, I had to do a rotation in Alaska. The application asked if I had ever been on psychotropic medications or in counseling. I had taken Zoloft $12.5 \mathrm{mg}$ for 90 days due to anticipatory anxiety about starting intern year. Fortunately, my fears weren't realized, so I stopped the medication when the prescription expired. I had also gone to counseling in my fourth year of medical school for a separate relationship issue. So, I answered both questions affirmatively. This resulted in my having to defend myself to a panel of people on the Alaska medical board over the phone. They granted my license, but it was a humiliating experience - and definitely created barriers to my seeking care moving forward-both because I have not wanted to be in a position to have to answer those types of questions affirmatively, and due to financial barriers because I will not use insurance to defray costs of counseling since that may be discoverable. What a horrible culture of shame those questions create!

Delaware begins with the same question as Alabama: Within the past 5 years, have you ever raised the issue of consumption of drugs or alcohol or the issue of a mental, emotional, nervous, or behavioral disorder or condition as a defense, mitigation, or explanation for your actions in the course of any administrative or judicial proceedings or investigation; any inquiry or other proceeding; or any proposed termination by an educational institution; employer; governmental agency; professional organization; or licensing authority?

Two follow-up questions include: Are such current conditions or impairments reduced or ameliorated because of ongoing treatment (with or without medication) or participation in a monitoring program or because of the field of practice, the setting, or the manner in which you have chosen to practice medicine? Do you have a mental or physical disability that limits your ability to practice medicine in a fully competent and professional manner with safety to patients? If yes, are you willing to accept a conditional or limited 
license to practice medicine if it is possible to accommodate such disability?

Final question: Do you agree to submit to an examination at your own expense if the Executive Director of the Board of Medical Licensure and Discipline deems it necessary to determine whether your physical and/or mental impairment presents a significant risk to the health or safety of patients or otherwise causes you not to be fully qualified to practice medicine in a competent and professional manner with safety to patients without limitations or accommodations? If no, submit a signed, notarized statement fully explaining your answer.
Delaware's application makes an anticipatory request that physicians waive their confidentiality/HIPAA rights and submit to an impairment exam at their own expense before the board reviews the application or meets with the physician.

Florida has 6 questions. Three relate to substance use and one to physical impairment. Two mental health questions are: In the last 5 years, have you been admitted or referred to a hospital, facility or impaired practitioner program for the treatment of a diagnosed mental disorder or impairment? During the past 5 years, have you been treated for or had a recurrence of a diagnosed mental health disorder that has impaired your ability

15. Has your ability to practice medicine in a competent and safe manner ever been impaired or limited by any condition, behavior, impairment, or limitation of a physical, mental, or emotional nature?

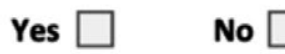

16. Are you currently experiencing any medical condition or disorder that impairs your judgment or that otherwise affects your ability to practice medicine in a safe and competent manner?

Yes $\square \quad$ No $\square$

17. Since completing your postgraduate training, have you ever been physically or mentally unable to practice medicine for a period of sixty $(60)$ or longer?

Yes $\square \quad$ No $\square$

18. Are you currently the subject of any civil investigation or court process relating to your ability to practice in a safe and competent manner?

Yes $\square \quad$ No

19. Have you ever been diagnosed with, been treated for, or do you currently have voyeurism, pedophilia, exhibitionism, or any other sexual behavior disorder? (Please note that "sexual behavior disorder" does not include sexual preference)

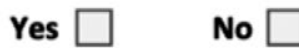

20. Are you currently engaged in the illegal use of any drug, whether by ingestion, injection, inhalation, or any other method?

Yes $\square \quad$ No $\square$

21. Have you used or are you currently using any chemical substance(s), legal or illegal, that in any way impaired or limited, or is currently impairing or limiting, your ability to practice medicine in a safe and competent manner?

Yes $\square \quad$ No

22. Have you ever been voluntarily or involuntarily committed or confined to any facility for mental health care?

23. Have you ever been diagnosed with, treated for, or do you currently have:

Yes $\square \quad$ No

Yes

No Check each condition you have ever been diagnosed with, treated for, or currently have:

$\square$ Bipolar Disorder
$\square$ Hypomania
$\square$ Schizophrenia
$\square$ Depression
$\square$ Seasonal Affective

$\begin{array}{ll}\square \text { Depressive Neurosis } & \square \text { Kleptomania } \\ \square \text { Any Dissociative Disorder } & \square \text { Pyromania } \\ \square \text { Any Psychotic Disorder } & \square \text { Delirium } \\ \square \text { Any Organic Mental Disorder } & \square \text { Paranoia } \\ \square \text { Any condition requiring chronic medical or behavioral treatment }\end{array}$

24. Have you ever taken, or are you currently taking, any controlled substance for any of these disorders?

Yes $\square \quad$ No

25. Have you ever been adjudicated, or declared incompetent, or been the subject of an incompetency proceeding?

Yes

No

Figure 1. Alaska image (from public document Alaska Medical Board Licensing Application 2019; https://www.commerce. alaska.gov/). 
to practice medicine? Neither of these questions focus on current impairment.

An affirmative answer to any question requires: A selfexplanation providing accurate details that include names of all physicians, therapists, counselors, hospitals, institutions, and/or clinics where you received treatment and dates of treatment. A report directed to the Florida Board of Medicine from each treatment provider about your treatment, medications, and dates of treatment. If applicable, include Diagnostic and Statistical Manual of Mental Disorders (DSM) DSMIII R/DSM IV/DSM IV-TR Axis I and II diagnosis(es) code(s), admission and discharge summary(s).

Two Florida physicians report:

When I applied for my Florida license it was delayed by months. I was required to have a psych evaluation by an approved doctor due my history of depression which was treated and well managed. It fell under the impaired physician program and definitely was stigmatizing. To this day I don't answer those questions honestly anymore and am hesitant to seek treatment as needed. After the unexpected death of a patient, I sought counseling. By a stroke of (bad) luck, I picked the only one in town in charge of impaired physician monitoring. He told the board (though stable) I should be monitored. I had to defend myself in front of the Florida board. They laughed in my face and then posted in the local newspapers that I was sentenced to 5 years of monitoring. I had mandatory Wednesday group therapy. Though I was an exemplary physician, my employers had to be told why I was unavailable for call every Wednesday. Each time I (re)credential with hospitals, I must explain the whole thing again. HIPAA for me does not exist. I have never missed a single day of work for mental health.

Massachusetts previously ranked an A with one straightforward question: Do you have a medical or physical condition that currently impairs your ability to practice medicine? Now Massachusetts asks 2 additional impairment-related questions related to substance use including: Have you ever refused to submit to a test to determine whether you had consumed and/or were under the influence of chemical substances? This section is preceded by a convoluted definition of currently meaning within the past 2 years (similar to Alabama). Following these questions is a large box titled 'Important note regarding physician wellness' with 4 paragraphs promoting the Massachusetts Medical Society's Physician Health Services (PHS) culminating with a statement that their state's physician health program is designed to assist physicians with the following: alcohol misuse; substance use disorder; behavioral or mental or physical health issues that cur- rently impair the ability to practice medicine; stress including administrative burdens; financial pressures; and work-family balance issues.

Recruiting physicians with occupational stress into the state's PHP on a medical licensing application is misplaced and predatory given the adverse impact of these health programs on the careers of physicians detailed in this report.

Mississippi application forces physicians to waive all confidentiality and HIPAA rights plus consent to a mental exam at applicant's expense. Similar to Delaware, Mississippi has this additional paragraph: By submission of an application for licensing to the Board, an applicant shall be deemed to have given his or her consent to submit to physical or mental examinations if, when and in the manner so directed by the Board and to waive all objections as to the admissibility or disclosure of findings, reports or recommendations pertaining thereto on the grounds of privileges provided by law. The expense of such examination shall be borne by the applicant.

Mississippi also asks: Have you ever been diagnosed as having, or have you ever been treated for, pedophilia, exhibitionism, or voyeurism, bipolar disorder, sexual disorder, schizophrenia, paranoia or other psychiatric disorder?

Given the forced breach of confidentiality, forced consent to exam, and have-you-ever been diagnosed with mental health conditions such as bipolar disorder unlinked to current impairment, Mississippi is graded F Rhode Island has no current impairment questions; however, there are 2 questions that may preclude a physician who suffered retaliation for a mental health condition during training from receiving a medical license. The first: During any Professional/Medical Education were you ever dismissed, suspended, restricted, put on probation, or otherwise acted against or did you take a leave of absence for medical reasons? The second: During any Post Graduate Training, were you ever dismissed, suspended, restricted, put on probation, or otherwise acted against or did you take a leave of absence for medical reasons?

Having to defend a leave of absence for medical reasons that may have happened decades ago re-victimizes physicians who have experienced punishment/retaliation for occupationally induced mental health conditions. One anesthesiologist explains:

When I became overwhelmed with abuse I was facing in residency, I begged my program director with tears running down my face for emergency mental health care. I spent the next few days isolated, confused, exhausted on my couch. I saw a counselor. I started an antidepressant for the first time in my 30 years of existence. By the weekend I felt refreshed with a glimmer of hope. When my program asked to meet with me on 
Monday, I was sure it was to see if I was okay, to ensure I had no thoughts of self-harm or suicide. I was wrong. The meeting was to let me know I was placed on 6 months' probation for being unprofessional. I was flabbergasted, my mouth literally fell open. I couldn't believe I was sitting in front of the people I trusted with my education and they were able to look at me in my greatest time of need and anguish knowing I was now in counseling and on medication and respond only with punishment.

Washington has Personal Data questions that cover mental health, substance use, and criminal/predatory behavior with a list of impairing medical conditions that match the Vermont application (Figure 2).

Though Washington asks about medical conditions linked to current impairment and rightfully screens physicians for predatory/criminal behavior, we find the threatening language in the black box to be concerning including forced breach of an applicant's confidentiality and privacy.

\section{Discussion}

The Federation of State Medical Boards (FSMB) defines impairment as a physical, mental, or substance-related disorder that interferes with a physician's ability to undertake professional activities competently and safely. ${ }^{6}$ The FSMB focus is the individual impaired physician. But what causes the impairment? Has the impairment been fixed? One psychiatrist explains:

Taking medication for Attention Deficit Hyperactivity Disorder (ADHD) is analogous to wearing

\section{Personal Data Questions}

1. Do you have a medical condition which in any way impairs or limits your ability to practice your profession with reasonable skill and safety? If yes, please attach explanation

"Medical Condition" includes physiological, mental or psychological conditions or disorders, such as, but not limited to orthopedic, visual, speech, and hearing impairments, cerebral palsy, epilepsy, muscular dystrophy, multiple sclerosis, cancer, heart disease, diabetes, intellectual disabilities, emotional or mental illness, specific learning disabilities, HIV disease, tuberculosis, drug addiction, and alcoholism.

If you answered yes to question 1, explain:

1a. How your treatment has reduced or eliminated the limitations caused by your medical condition.

1b. How your field of practice, the setting or manner of practice has reduced or eliminated the limitations caused by your medical condition.

Note: If you answered "yes" to question 1, the licensing authority will assess the nature, severity, and the duration of the risks associated with the ongoing medical condition and the ongoing treatment to determine whether your license should be restricted, conditions imposed, or no license issued.

The licensing authority may require you to undergo one or more mental, physical or psychological examination(s). This would be at your own expense. By submitting this application, you give consent to such an examination(s). You also agree the examination report(s) may be provided to the licensing authority. You waive all claims based on confidentiality or privileged communication. If you do not submit to a required examination(s) or provide the report(s) to the licensing authority, your application may be denied.

2. Do you currently use chemical substance(s) in any way which impair or limit your ability to practice your profession with reasonable skill and safety? If yes, please explain.

"Currently" means within the past two years.

"Chemical substances" include alcohol, drugs, or medications, whether taken legally or illegally.

3. Have you ever been diagnosed with, or treated for, pedophilia, exhibitionism, voyeurism or frotteurism?.

Figure 2. Washington image (from public document Washington Medical Commission Licensing Application 2019; https://wme. wa.gov/). 
glasses for my nearsightedness. My state licensing question asks: Do you have a condition that could impact your abilities? As long as I am wearing my glasses I can see. As long as I am taking my ADHD medicine I can keep fairly focused. What business is it of theirs? Normally I feel guilty for lying about the slightest thing. I was counseled behind closed doors by a faculty who knew of my struggles with ADHD to simply put no on the form and leave it at that. This proved to be good advice. I was raised to be extremely honest about everything. When it comes to completing these questions for licensing I believe I am being honest because I was instructed by my respected faculty member to look at the questions in this light: Are you impaired by your condition? No. Then the answer on the application is NO.

Many states treat illness as impairment. According to the FSMB: Some regulatory agencies equate illness (i.e., addiction or depression) as synonymous with impairment. Physician illness and impairment exist on a continuum with illness typically predating impairment, often by many years. This is a critically important distinction. Illness is the existence of a disease. Impairment is a functional classification and implies the inability of the person affected by disease to perform specific activities. ${ }^{6}$

FSMB believes illness precedes impairment and that physicians may at any point fall into the continuum of inability to practice medicine competently and safely.

Medical board intervention is always directed at the physician, not the system. But what if the system causes physician impairment? Case in point: Resident physicians are legally forced to work 28-hour shifts (or longer due to unenforced caps). ${ }^{7}$ Working just 17 hours is equivalent to the cognitive and psychomotor impairment of a $0.05 \%$ blood alcohol content (illegal to drive in Utah and most Western European countries). Working beyond 24 hours is equivalent to a $0.10 \%$ blood alcohol content (exceeding the $0.08 \%$ legal limit to drive in 49 states and District of Columbia). Impairment escalates along a continuum and is noted even at 10 hours. ${ }^{8}$ Sleep-deprivation-related cognitive and psychomotor impairment leads to medical mistakes and fatal car accidents after long hospital shifts.?

Professional boards are tasked with protecting the public. To prevent pilot fatigue resulting in impairmentrelated plane crashes, the National Transportation Safety Board (NTSB) limits maximum flight time to 9 hours during the day or 8 hours at night. Why force physicians to work 3 times that amount?

As guardians of public safety, medical boards (like transportation boards) must address hazardous work conditions that currently impair more than 130,000 US resident physicians. ${ }^{9}$ Given our physician shortage, boards should protect physicians from sleep-deprivation-related seizures, hallucinations, psychosis and death inside our hospitals. We cannot afford to lose one more doctor.
Beyond sleep deprivation, physicians are injured by chronic violations of their human rights in hospitals due to overwork (80-100 hours work week is equivalent to 2 to 3 full-time jobs), food/water deprivation, bullying, harassment, discrimination, and punishment when sick (including lack of confidential mental health care). ${ }^{5}$ Late-stage effects of these violations are substance abuse and mental illness.

Rather than address the systemic causes of physician impairment, medical boards too often sanction physicians thereby re-victimizing victims.

Some board questions seem more voyeuristic and predatory than helpful, exploiting vulnerable physicians for profit. Fine-print warnings threaten hefty fines for intentional or inadvertent non-disclosure leading naively honest physicians to answer ADA-noncompliant questions by sharing intimate confidential information when they present no danger to patients. Sanctioned physicians risk public disclosure of their mental health conditions. One affirmative answer creates a cascade effect in which non-impaired physicians are further traumatized and may be mandated to multi-year addiction recovery programs (even though they have never used drugs). When one state denies or limits licensure, others mirror the action. One positive response to a mental health question may follow an applicant for life.

\section{Conclusions}

Medical boards do undermine physician mental health by breaching physician confidentiality and privacy. Qualified, competent applicants who disclose mental health conditions do suffer discrimination by medical boards. Many state medical boards ask questions about physical and mental health in violation of Title II regulations of the Americans with Disabilities Act of 1990, nearly 30 years after enactment of the law. In their search for criminal behavior among physicians, medical boards must not become criminal in their own behavior. By breaking federal law, physicians' civil rights, and the AMA Code of Ethics, boards have weaponized mental health diagnoses against physicians. Recommendations for all medical boards: i) Remove mental health questions from medical licensing applications. Replace with current functional impairment questions such as: Do you currently have a condition that impairs your ability to practice medicine safely? Comply with federal law by following best practices of Grade A states. Move criminal/predatory conduct such as voyeurism queries to the criminal section; ii) Address impairment from hazardous working conditions. Rather than focus on individual victims, engage in high-yield activities that resolve hazardous conditions impairing physicians en masse. To truly protect patients, align with all other industries invested in public safety that have legislated and enforced maximum 16-hour shifts, 60-hour work weeks, with minimum 30 -minute breaks every 8 
hours; iii) Encourage non-punitive 100\% confidential mental health care. Physicians require safe, accessible mental health care to be well-adjusted human beings. Most physicians enter medicine as humanitarians with noble intentions. Help them be well. After all, how can physicians give patients the care they've never received? One surgeon summarizes:

Physicians are treated as criminals and tracked more closely than Level 3 sex offenders. Answering all these questions on applications, the subtle, unspoken lesson is you had better be squeaky clean, mentally, morally and physically! If you step off the shining path, bad things will occur. I have known 7 male physicians who died by suicide. Most with a happy exterior. Why? They cannot confide in colleagues for fear that their colleagues will turn them in to hospitals and boards - and there goes their privileges and livelihood. They cannot confide in their spouses because during rough patches mentally, their marriages are already in trouble. If they share psychological problems, they probably fear that the wife may use this as ammunition in any future divorce. So, they keep on smiling - right up to the hour they die.

Even until their last breath, physicians retain their work ethic. Some doctors are completing chart notes, returning lab results, and checking in on hospitalized patients in the hours before their suicides. ${ }^{5}$

By injuring physicians, we are not protecting the public.

Let's end the physician mental health witch hunt.

\section{References}

1. Vogel L. Has suicide become an occupational hazard of practicing medicine? CMAJ 2018;190:E752-3.

2. Pereira-Lima K. residency program factors associated with depressive symptoms in internal medicine interns: a prospective cohort study. Acad Med 2019;94:869-75.

3. Anderson P. Doctors' Suicide Rate Highest of Any Profession. American Psychiatric Association annual meeting 2018. Available from: https://www.webmd.com/mentalhealth/news/20180508/doctors-suicide-rate-highest-of-anyprofession\#1

4. Wible P. Do physician health programs increase physician suicides? Medscape 2015. Available from: https://www. medscape.com/viewarticle/850023

5. Wible P. Human Rights Violations in Medicine: A-to-Z Action Guide. Pamela Wible, M.D. 2019.

6. Federation of State Medical Boards. Policy on Physician Impairment. Available from: https://www.fsmb.org/siteassets/ advocacy/policies/physician-impairment.pdf

7. Wible P. Sleep-deprived doctors disclose hospital horrors. Pamela Wible, M.D. 2017. Available from: https:/www.i dealmedicalcare.org/sleep-deprived-docs-disclose-hospitalhorrors/

8. Dawson D, Reid K. Fatigue, alcohol and performance impairment. Nature. 1997;388:235.

9. Association of American Medical Colleges. Physician Speciality Data Report. [Internet]. ACGME residents and fellows by sex and specialty, 2017. Available from: https://www.aamc.org/data-reports/workforce/interactivedata/acgme-residents-and-fellows-sex-and-specialty2017?fbclid=IwAR21 ckjgb8UedW11y3131w9B5Qv0ysZR wXlvfguaba6tgo53St4_d3SLjXo 